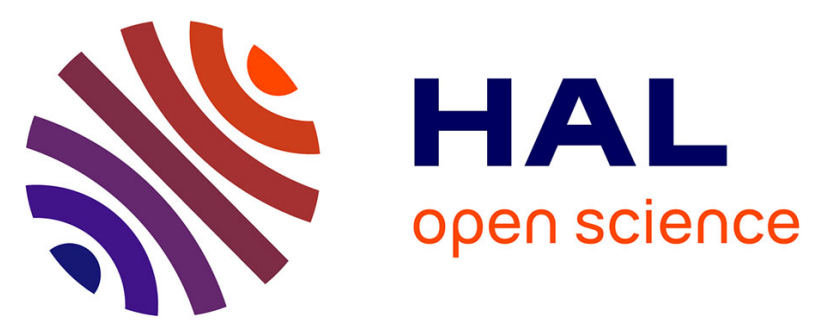

\title{
From ferrocene to fluorine-containing penta-substituted derivatives and all points in-between; or, how to increase the available chemical space
}

Mehdi Tazi, William Erb, Thierry Roisnel, Vincent Dorcet, Florence Mongin, Paul J Low

\section{To cite this version:}

Mehdi Tazi, William Erb, Thierry Roisnel, Vincent Dorcet, Florence Mongin, et al.. From ferrocene to fluorine-containing penta-substituted derivatives and all points in-between; or, how to increase the available chemical space. Organic \& Biomolecular Chemistry, 2019, 17 (42), pp.9352-9359. 10.1039/c9ob01885a . hal-02364875

HAL Id: hal-02364875

https://hal-univ-rennes1.archives-ouvertes.fr/hal-02364875

Submitted on 20 Mar 2020

HAL is a multi-disciplinary open access archive for the deposit and dissemination of scientific research documents, whether they are published or not. The documents may come from teaching and research institutions in France or abroad, or from public or private research centers.
L'archive ouverte pluridisciplinaire HAL, est destinée au dépôt et à la diffusion de documents scientifiques de niveau recherche, publiés ou non, émanant des établissements d'enseignement et de recherche français ou étrangers, des laboratoires publics ou privés. 


\title{
From ferrocene to fluorine-containing penta-substituted derivatives and all points in-between; or, how to increase the available chemical space
}

\author{
Mehdi Tazi, ${ }^{a}$ William Erb, ${ }^{* a}$ Thierry Roisnel, ${ }^{a}$ Vincent Dorcet, ${ }^{a}$ Florence Mongin ${ }^{a}$ and Paul J. Low ${ }^{b}$

\begin{abstract}
In spite of the growing interest in fluorine-containing compounds, and the improvements in materials, optical and biological properties that can arise from substitution of a phenyl ring by ferrocene within a molecular scaffold, synthetic strategies that allow the efficient preparation of fluoroferrocene derivatives are scarce. Following conversion of ferrocene to fluoroferrocene, we have developed routes to fluorine-containing di-, tri-, tetra- and penta-substituted ferrocene derivatives to extend the available chemical space. Our approach is based on the identification of suitable reagents and conditions to achieve fluorine-directed deprotometalation, and exploitation of the halogen 'dance' rearrangement in the ferrocene series.
\end{abstract}

\section{Introduction}

Substitution of one (or more) hydrogen atom(s) in a molecular structure by fluorine has been shown to have a positive influence on a truly surprising range of properties of relevance to the materials, ${ }^{1}$ agrochemical and pharmaceutical arenas. ${ }^{2}$ For example, incorporating a fluorine atom into a pharmaceutically active molecular scaffold can contribute to increased pharmaceutical effectiveness, biological half-life and bio-absorption..$^{2-3}$ Thus, it is no coincidence that many drugs already on the market have fluorine in their structure, for example Trametinib (a MEK inhibitor to treat patients suffering from a form of melanoma), Vonoprazan (a potassiumcompetitive acid blocker to treat acid-related diseases) and Delpazolid, an antibiotic in clinical trials to treat mycobacterial infections including drug-resistant tuberculosis (Fig. 1). ${ }^{2,4}$ While approaches based on virtual screening have been developed for small molecule drug discovery, ${ }^{5}$ increasing the "available chemical space" 6 and developing synthetic access to new scaffolds containing fluorine remains a topic of great interest.

In seeking to expand chemical space and optimize the material, optical and biological properties of small molecules, attention has also been given to inclusion of ferrocene moieties within molecular designs. Ferrocene is a three-dimensional unit, stable to air, water, heat and light, and able to undergo facile and reversible one-electron oxidation. Therefore, inclusion of ferrocene within a molecule can be used to introduce, augment or tune many physical and chemical properties. ${ }^{7}$ As a consequence, ferrocene-based materials have for example been developed for their nonlinear optical or conducting properties and as photo-switchable polymers. In addition, various ferrocene-based systems have been designed for use as sensors, ${ }^{7 a}$ or incorporated into compounds for applications in catalysis. ${ }^{8}$ Ferrocene derivatives are also employed as burn rate modifiers and additives in rocket propellants, ${ }^{9}$ and ferrocenebased compounds are also expected to have applications in agriculture, for example as agrochemicals and for soil remediation. ${ }^{7 a}$

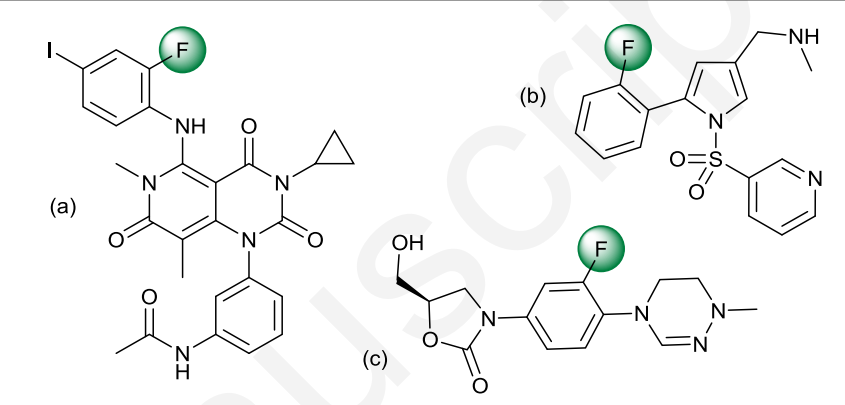

Fig. 1. The pharmaceutically-active, fluorine-containing compounds (a) Trametinib; (b) Vonoprazan; and (c) Delpazolid.

When incorporated into a bioactive molecule, ferrocene can increase the lipophilicity, aiding the passage through biological barriers. ${ }^{10}$ Consequently, ferrocene has been progressively established as a good bioisostere for the aryl or heteroaryl ring. ${ }^{7 a, 10-11}$ As a result, it has attracted the interest of medicinal chemists, and ferrocene is currently present in compounds with a wide range of bioactivities. For instance, ferrocifens are a promising family of anticancer drug candidates. ${ }^{12}$ Ferroquine is in clinical trials for use in combination with artefenomel to treat chloroquine-resistant forms of malaria, ${ }^{13}$ but also represents a promising candidate for cancer therapeutics. ${ }^{14}$

A combination of these strategies has led to interest in the compounds featuring both ferrocene and fluorine (Fig. 2), which can lead to further improvement in the biological properties. ${ }^{7 a}$ However, probably due to the lack of efficient methods to access them, the biological properties of compounds in which fluorine is directly linked to ferrocene have to our knowledge never been evaluated. Thus, our goal is here to open synthetic ways to fluorine-containing polysubstituted ferrocenes, consequently extending the "available chemical space" to these new scaffolds. 

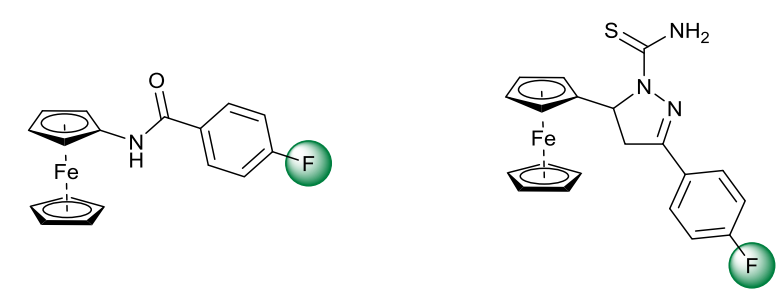

Fig. 2. Compounds identified for their cytotoxic activity against MDA-MB-435-S-F breast cancer cells (left) or their anti-amoebic activity (right).

The preparation of the parent fluoroferrocene (1) from bromoferrocene, via halogen/lithium exchange and trapping of the lithioferrocene with perchloryl fluoride, was first described by Hedberg and Rosenberg in $1971 .{ }^{15}$ However, despite this precedence and the contemporary interest in fluorine and ferrocene containing small molecules, surprisingly few fluoroferrocene derivatives have been reported since. ${ }^{16}$ This might be due in part to the warning of Peet and Rockett who experienced an explosion when perchloryl fluoride was used to intercept the lithio compound generated from (dimethylamino)methylferrocene. ${ }^{17}$ Nevertheless, the use of $\mathrm{N}$ fluorobenzenesulfonimide (NFSI) as an alternative electrophilic fluorinated agent by Sünkel and Weigand in 2011 has renewed interest in synthetic routes to fluoroferrocenes. ${ }^{18}$ Consequently, modern routes now allow ferrocene to be used directly as a starting material in the preparation of $\mathbf{1}$ by direct deprotometalation followed by trapping with NFSI. ${ }^{19}$ Similar strategies afford 1,2-difluoroferrocene, ${ }^{19 a}$ as well as 1,2,3,4,5pentafluoroferrocene, albeit the latter in low-yield. ${ }^{19 a}$

However, while 1,1'-difluoroferrocene could be obtained in $10 \%$ yield from $1,1^{\prime}$-dibromoferrocene, ${ }^{19 b}$ and in $2 \%$ yield from ferrocene, ${ }^{19 \mathrm{c}}$ other fluoroferrocenes (1,2,3-trifluoro, ${ }^{19 a}$ 1,2,3,4tetrafluoro, ${ }^{19 a}$ and 1,1',2,3,4,5-hexafluoroferrocene by consecutive deprotometalation-trapping sequences, ${ }^{19 a}$ and $1-$ bromo-2-fluoroferrocene by bromine/lithium exchange followed by trapping ${ }^{20}$ ) have been formed, but not isolated. To the best of our knowledge, few studies of the subsequent functionalization of $\mathbf{1}$ have been described.

This paper reports the results of a study dedicated to the functionalization of fluoroferrocene $(\mathbf{1})$ by a deprotolithiationtrapping sequence, ${ }^{21}$ coupled with the isomerization of iodo derivatives of $\mathbf{1}$ using the halogen 'dance' reaction. ${ }^{22}$ Following communication of preliminary results, ${ }^{23}$ details are now given from a more comprehensive study of the scope of the synthetic methodology, which gives convenient access to a wide range of hitherto unknown functionalized fluoroferrocene derivatives.

\section{Results and discussion}

With a view to developing a convenient procedure to 2substituted fluoroferrocenes $\mathbf{2}$, the key reagent fluoroferrocene (1) was initially prepared by deprotometalation of ferrocene in the presence of tert-butyllithium and catalytic potassium tertbutoxide in tetrahydrofuran (THF) at $-75^{\circ} \mathrm{C}$ for $1 \mathrm{~h}, 24$ followed by reaction with NFSI in THF at $-20{ }^{\circ} \mathrm{C} .{ }^{19}$ After optimization, 1 could be isolated in about $50 \%$ yield (Scheme 1 ).

As fluoroferrocene (1) is not prone to nucleophilic attack, a wide range of strong bases may in principle be employed to effect the second deprotonation step before subsequent trapping of the resulting 2-metalated fluoroferrocene. Deprotonation of 1 by sec-butyllithium (1.2 equivalents), a base already employed to efficiently deprotonate fluorobenzene, ${ }^{25}$ was found complete after $1 \mathrm{~h}$ in THF at $-75^{\circ} \mathrm{C}$, as determined by subsequent deuteration ( $2 \mathrm{a}$ obtained in $98 \%$ yield and $>95 \%$ deuterium incorporation). The interception of 1-fluoro-2lithioferrocene $([\mathbf{1}-\mathrm{H}] \mathrm{Li})$ in situ worked efficiently with a large range of electrophiles to give the compounds 2 (Scheme 1 ). Thus, reaction of $[\mathbf{1}-\mathbf{H}] \mathbf{L i}$ with allyl bromide gave the vinyl $\begin{array}{llll}\text { compound } \quad \mathbf{b} & \text { (39\%), whilst with }\end{array}$ dimethylmethylideneammonium iodide (Eschenmoser's salt) the amine $2 \mathrm{c}(80 \%)$ sought by Peet and Rockett was obtained, pleasingly without the violent explosion reported from these earlier studies. ${ }^{17}$ After transmetalation to zinc, the Negishistyle ${ }^{26}$ palladium-catalyzed cross-coupling reaction of $[\mathbf{1}-\mathbf{H}] \mathbf{L i}$ with 2 -chloropyridine gave $\mathbf{2 d}$ (61\%). The boronic ester $\mathbf{2 e}$ (67\%, Fig. 3) was isolated following sequential reaction of [1-H]Li with triisopropyl borate and pinacol. Reactions of $[\mathbf{1}-\mathbf{H}] \mathbf{L i}$ with aliphatic and aromatic aldehydes gave the secondary alcohols $\mathbf{2 f - h}$, with a modest degree of stereochemical selectivity, whilst reactions with ketones yielded the expected tertiary alcohols $\mathbf{2} \mathbf{i}$ (71\%) and $\mathbf{2 j}$ (72\%). A further range of carbonyl compounds were obtained from [1-H]Li and dimethylformamide (aldehyde 2k, 97\%), 2-methoxybenzoyl chloride (ketone 2l, 60\%), carbon dioxide (carboxylic acid $2 \mathrm{~m}, 72 \%$ ), and phenyl isocyanate (carboxamide $2 \mathrm{n}, \mathbf{8 3} \%$ ). The family 1,2-dihaloferrocenes was also obtained following reaction of [1-H]Li with the electrophilic halogenating agents NFSI (1,2-difluoroferrocene 20, 72\%), hexachloroethane (1-chloro-2-fluoroferrocene 2p, 92\%), tetrabromomethane (1-bromo-2-fluoroferrocene $\mathbf{2 q}, 92 \%$ ) and iodine (1-fluoro-2-iodoferrocene $2 r$, 96\%). The Group 4, 5 and 6 derivatives $\mathbf{2 s - v}$ were similarly prepared from [1-H]Li with chlorotrimethylsilane (trimethylsilane 2s, 96\%), chlorodiphenylphosphine (diphenylphosphine 2t, 61\%, crystallographically characterized as the $\mathrm{BH}_{3}$ adduct, Fig. 3), phenyl disulfide (phenylsulfide 2u, 97\%), and tributylchlorostannane (tributylstannane $\mathbf{2 v}, 89 \%$ ). 

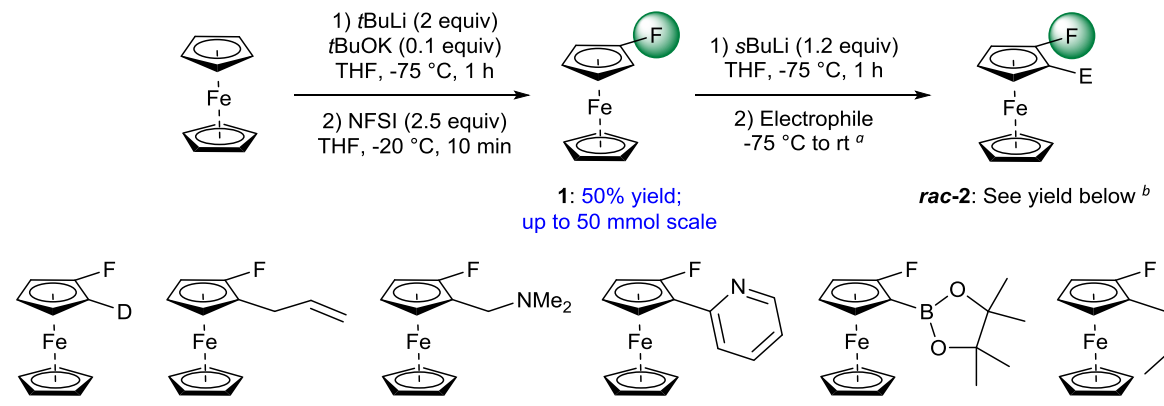

2b: $39 \%$

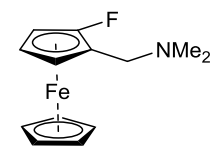

2c: $80 \%$

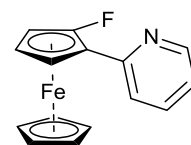

2d: $61 \%$

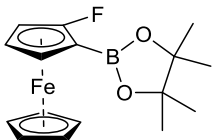

2e: $67 \%$

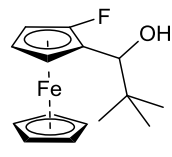

2f: $99 \%$

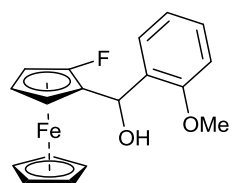

2g: $88 \%$ (72:28 d.r.)
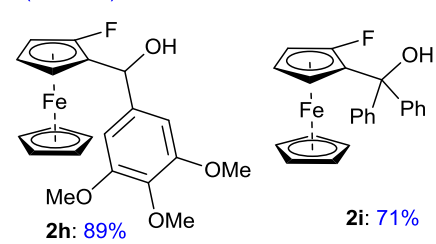

2i: $71 \%$

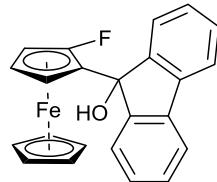

2j: $72 \%$

(56:44 d.r.)
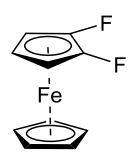

2o: $72 \%$
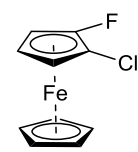

2p: $92 \%$

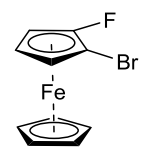

2q: $92 \%$

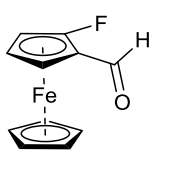

2k: $97 \%$

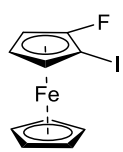

2r: $96 \%$

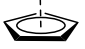

2s: $96 \%$

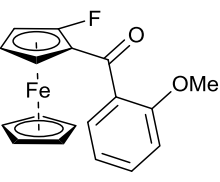

2l: $60 \%$

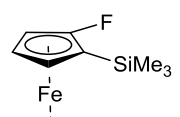

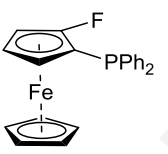

2t: $61 \%$

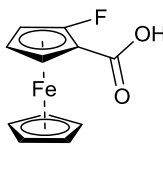

2m: $72 \%$

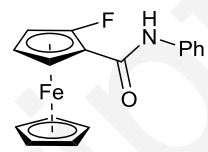

2n: $83 \%$

Scheme 1 Synthesis of fluoroferrocene (1) and 2-substituted fluoroferrocenes $\mathbf{2} .{ }^{a}$ See ESI for more details on the electrophilic trapping and subsequent hydrolysis. ${ }^{b}$ Yields are given after purification, as described in ESI.

Table 1. Synthesis of 1,3-disubstituted 2-fluoroferrocenes $\mathbf{3}$

(

${ }^{a}$ See ESI for more details on the electrophilic trapping and subsequent hydrolysis. ${ }^{b}$ Yields are given after purification, as described in ESI. 


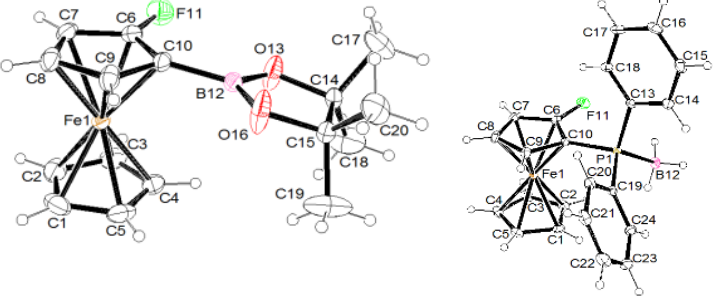

Fig. 3. ORTEP diagrams ( $30 \%$ probability) of compounds $\mathbf{2 e}$ and $\mathbf{2 t} \cdot \mathbf{B H}_{\mathbf{3}}$.

The subset of 2 -substituted fluoroferrocenes $\mathbf{2 p}, \mathbf{2} \mathbf{s}$ and $\mathbf{2 u}$ were chosen as platforms to demonstrate the introduction of a third substituent onto the ferrocene periphery. These substrates were selected as they undergo deprotonation at the increasingly functionalized $\mathrm{Cp}$ ligand by sec-butyllithium, rather than entering into reaction with the functional groups already present. Under the conditions employed to functionalize fluoroferrocene (1), fluorine-directed deprotonation of $\mathbf{2 p}, \mathbf{2 s}$, $2 \mathbf{u}$ and trapping gave a range of different 1,3-disubstituted 2fluoroferrocenes in yields ranging from $61 \%$ to quantitative (Table 1; Fig. 4). To broaden the scope of the protocols, the iodide $\mathbf{2}$ r, for which the use of an alkyllithium to deprotonate is excluded, was deprotonated by reaction with LiTMP (TMP = $2,2,6,6$-tetramethylpiperidino) in THF at -40 or $-80^{\circ} \mathrm{C}$; subsequent iodolysis yielded the symmetrical ferrocene $\mathbf{3 r}-\mathbf{I}$, which was isolated in $62 \%$ and $83 \%$, respectively. As the rest of the material proved to be the starting material, the deprotolithiation step was also carried out in the presence of $\mathrm{ZnCl}_{2}$.TEMDA (TMEDA $=N, N, N^{\prime}, N^{\prime}$-tetramethylethylenediamine) as an in situ trap, ${ }^{27}$ providing $3 \mathbf{3}-\mathbf{I}$ in quantitative yield (Scheme 2).
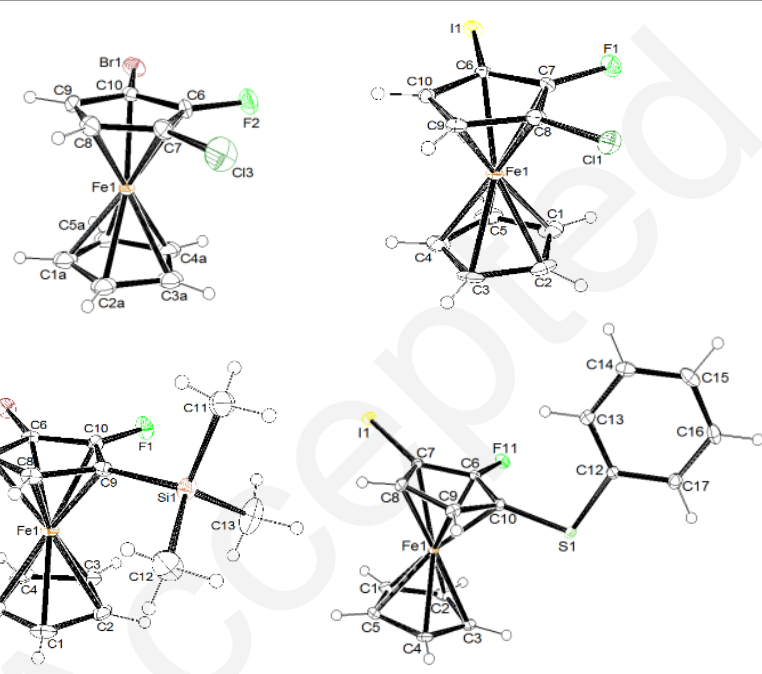

Fig. 4. ORTEP diagrams (30\% probability) of compounds $3 \mathrm{p}-\mathrm{Br}, \mathbf{3 p}-\mathrm{I}, \mathbf{3 s}-\mathbf{B r}$ and $3 \mathbf{u}-\mathbf{I}$.

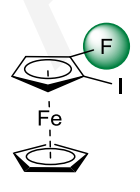

rac-2r
1) $\mathrm{ZnCl}_{2} \cdot \mathrm{TMEDA}$ (1 equiv) 2) LiTMP (1.5 equiv) THF, $-40^{\circ} \mathrm{C}, 2 \mathrm{~h}$

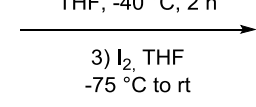
$-75^{\circ} \mathrm{C}$ to rt

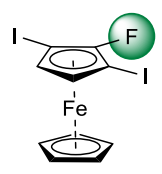

3r-I: Quant.
Scheme 2. Synthesis of 2-fluoro-1,3-diiodoferrocene (3r-1).

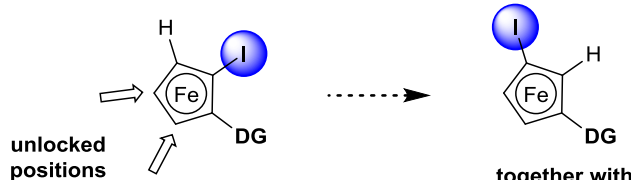

together with DG $=\mathrm{Cl}, \mathrm{Br}, \mathrm{I},{ }^{22 \mathrm{j}} \mathrm{CONR}_{2}{ }^{22 \mathrm{k}}$ side products

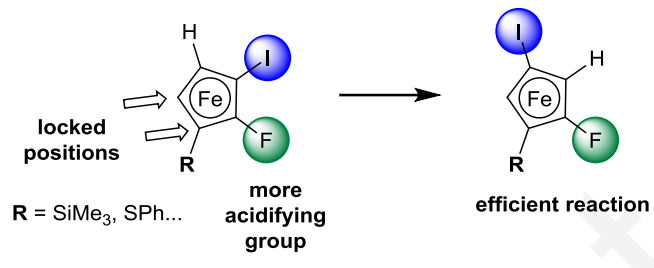

Fig. 5. Schematic representation of points of control leading to more selective halogen 'dance' reactions.

Whilst the sequential fluorine-directed deprotonation of $\mathbf{1}$ served as a convenient synthetic methodology for the preparation of 1,2-di and 1,2,3-trisubstituted ferrocenes ( 2 and 3 , respectively), the preparation of other patterns requires further consideration. The halogen 'dance' is an elegant way to isomerize brominated or iodinated aromatic and heteroaromatic compounds. ${ }^{22}$ The reaction, performed in the presence of hindered dialkylamides such as LiTMP and LiDA (DA = diisopropylamino) is driven by the formation of the most stable lithio compound. In the benzene series, various directing groups have been tested for their ability to influence the relative stability of these intermediate lithio species, with halogens, trifluoromethyl groups and oxygen-based substituents proving particularly effective. ${ }^{22 i}$ Whilst finding increasing applications in aryl and heteroaryl chemistry, the use of halogen dance strategies in the synthesis of ferrocene derivatives is still in its infancy. Chlorine, bromine and iodine were first tested as directing groups by Wang, Weissensteiner and co-workers, but the complexity of the reaction mixtures together with the high lipophilicity of the components limited the scope of the reaction. ${ }^{22 j}$ Some of the present authors have recently evaluated $\mathrm{N}, \mathrm{N}$-dialkyl carboxamides as directing group in the halogen dance rearrangement of halogenated ferrocenes; however limited selectivity was achieved due to competition in the directing abilities of the halogen and carboxamide moieties. ${ }^{22 k}$ Given the excellent selectivity observed in preparation of compounds $\mathbf{2}$ and $\mathbf{3}$, further efforts were made to explore the role of fluorine as a directing group ${ }^{28}$ in the halogen dance reaction on ferrocene scaffolds. With due consideration to the potential for competitive deprotonation, the presence of a non-directing substituent $\mathrm{R}$ blocking one site adjacent to the fluorine directing group was explored (Fig. 5).

Thus, in order to progress toward 2,4-disubstituted 1fluoroferrocenes, the 1,2,3-trisubstituted ferrocenes $3 \mathrm{~s}-\mathrm{I}, 3 \mathrm{~s}-\mathrm{Br}$ and $3 \mathrm{r}-\mathrm{I}$ were treated with LiTMP in THF at $-50{ }^{\circ} \mathrm{C} ; 22 \mathrm{k}$ the reaction was allowed to proceed for $2 \mathrm{~h}$ at the same temperature before being quenched by addition of methanol to give the rearranged products $4 \mathbf{s}-\mathbf{I}, \mathbf{4 s -} \mathbf{B r}$ and $\mathbf{4 r}-\mathbf{I}$, respectively (Scheme 3). Only a single migration was observed from symmetrical diiodide $3 r-\mathbf{I}$, even when using 2 equivalents of base (Fig. 6). 


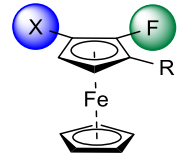

$$
\begin{aligned}
& \text { 1) LiTMP (1.1 equiv) } \\
& \underset{\text { THF, }-50{ }^{\circ} \mathrm{C}, 2 \mathrm{~h}}{\stackrel{2}{2} \mathrm{MeOH},-50{ }^{\circ} \mathrm{C}{ }^{a}}
\end{aligned}
$$

rac-3 or 3

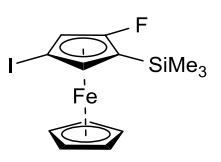

4s-1: $77 \%$

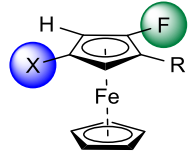

rac-4: See yield below

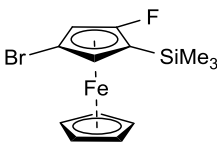

4s-Br: $63 \%$

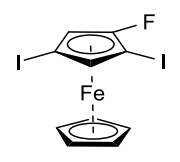

4r-I: $90 \%{ }^{c}$

Scheme 3. Synthesis of 2,4-disubstituted 1-fluoroferrocenes 4. ${ }^{a}$ See ESI for more details. ${ }^{b}$ Yields are given after purification, as described in ESI. ${ }^{c} 2$ equivalents of LiTMP were used.
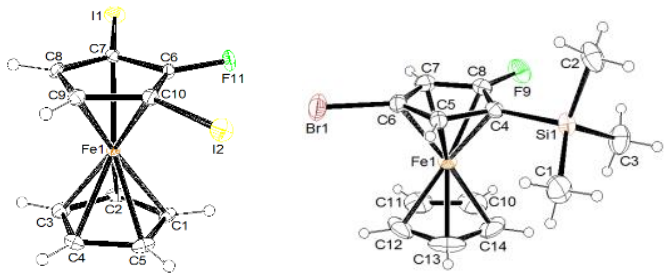

Fig. 6. ORTEP diagrams (30\% probability) of compounds $3 \mathrm{r}-\mathbf{I}$ and $4 \mathbf{s}-\mathbf{B r}$.

In order to progress toward tetrasubstituted ferrocenes, an attempt was made to trap the lithio compound formed from rearrangement of 3s-I. The sequence of 'halogen dancetrapping' reactions successfully led to a range of 1,3,4trisubstituted 2-fluoroferrocenes from a range of electrophilic traps (Table 2; Fig. 7). Thus, in a manner similar to that described for compounds 2, trapping of the rearranged lithio compound derived from 3s-I with Eschenmoser's salt gave fluoroamine $\mathbf{5 s - 1 - 1}$. The alcohols $\mathbf{5 s - 1 - 2}$ and $\mathbf{5 s - 1 - 3}$ were obtained from trapping with 2-anisaldehyde and benzophenone, respectively, whilst aldehyde $\mathbf{5 s - 1 - 4}$ was successfully obtained from dimethylformamide. The parent carboxylic acid $\mathbf{5 s - 1 - 5}$ was isolated following reaction with carbon dioxide, the carboxamide 5s-1-6 from dimethylcarbamoyl chloride, the phosphine 5s-1-7 from chlorodiphenylphosphine and sulfide 5sI-8 from phenyl disulfide. However, the limited stability of $\mathbf{5 s - 1 -}$ 5 in solution made isolation difficult and low-yielding, whilst purification of 5s-1-6 and 5s-1-8 was made challenging due to the low solubility in the apolar solvents required as eluent, resulting in inefficient separations by column chromatography. ${ }^{29}$

Table 2. Synthesis of 1,3,4-trisubstituted 2-fluoroferrocenes 5 .

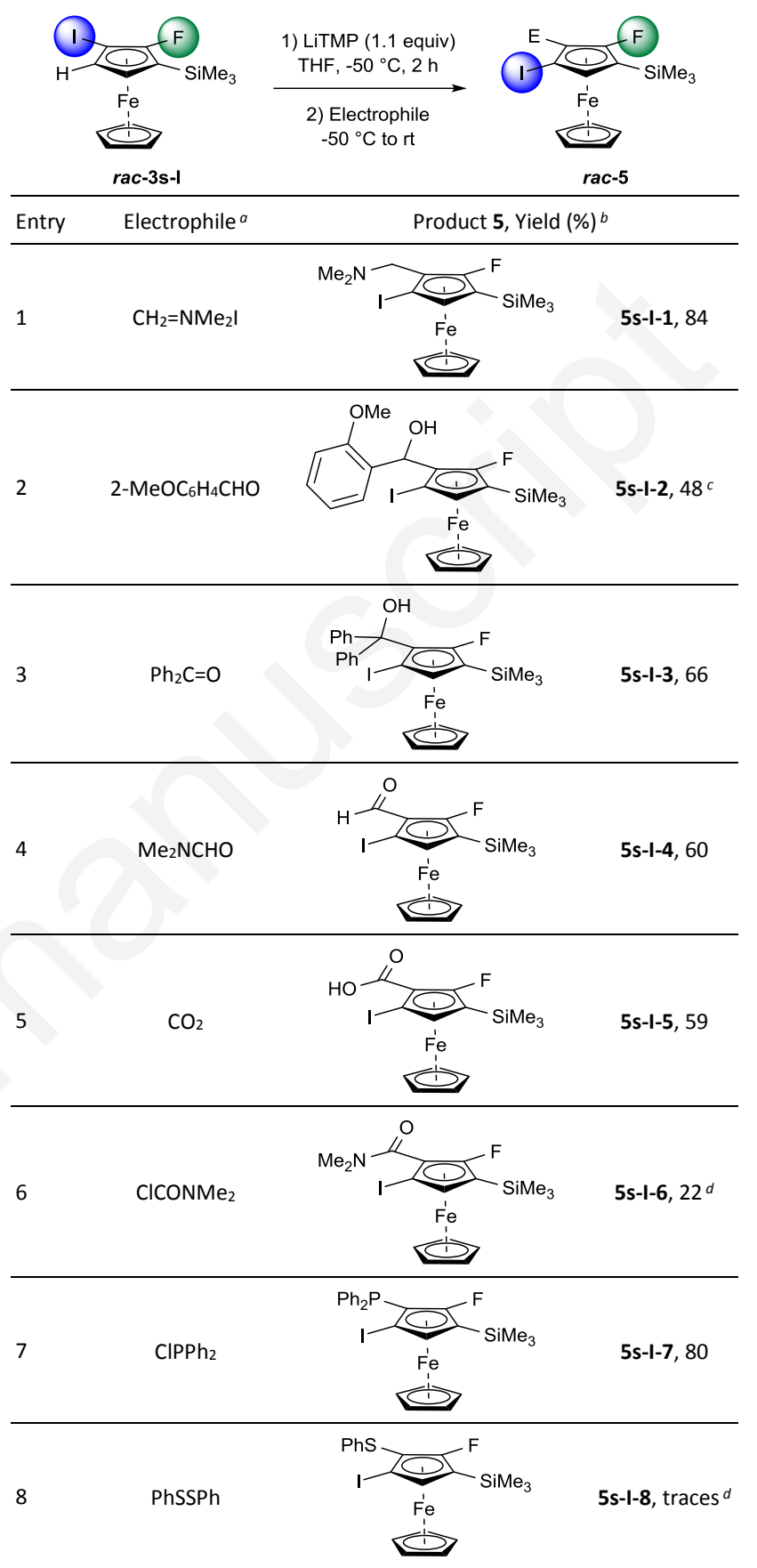

a See ESI for more details on the electrophilic trapping and subsequent hydrolysis. ${ }^{b}$ Yields are given after purification, as described in ESI. ${ }^{c}$ Mixture of diastereoisomers. ${ }^{d}$ Low yield due to difficult purification.

The use of the trimethylsilyl blocking group to promote selectively the halogen dance reactions yielding 1,2,4trisubstituted ferrocenes 4 prompted consideration of preparative routes to 3-substituted 1-fluoroferrocenes, which are to our knowledge a completely new family. Treatment of 2,4-disubstituted 1-fluoroferrocenes $4 \mathrm{~s}-\mathrm{I}$ and $4 \mathrm{~s}-\mathrm{Br}$ with tetrabutylammonium fluoride $(\mathrm{THF}, \mathrm{rt}, 30 \mathrm{~min})^{30}$ gave the desired 1,3-dihalogeno products $6 \mathrm{~s}-\mathbf{I}$ and $6 \mathrm{~s}-\mathrm{Br}$, which were 
isolated in high yield (Scheme 4). Similarly, from 1-chloro-4iodo-2-(trimethylsilyl)ferrocene $\quad\left(4 s^{\prime}-1\right)$, ${ }^{23 a}$ 1-chloro-3iodoferrocene $\left(6 s^{\prime}-1\right)$ was formed in quantitative yield, demonstrating generality of this approach (Scheme 4).
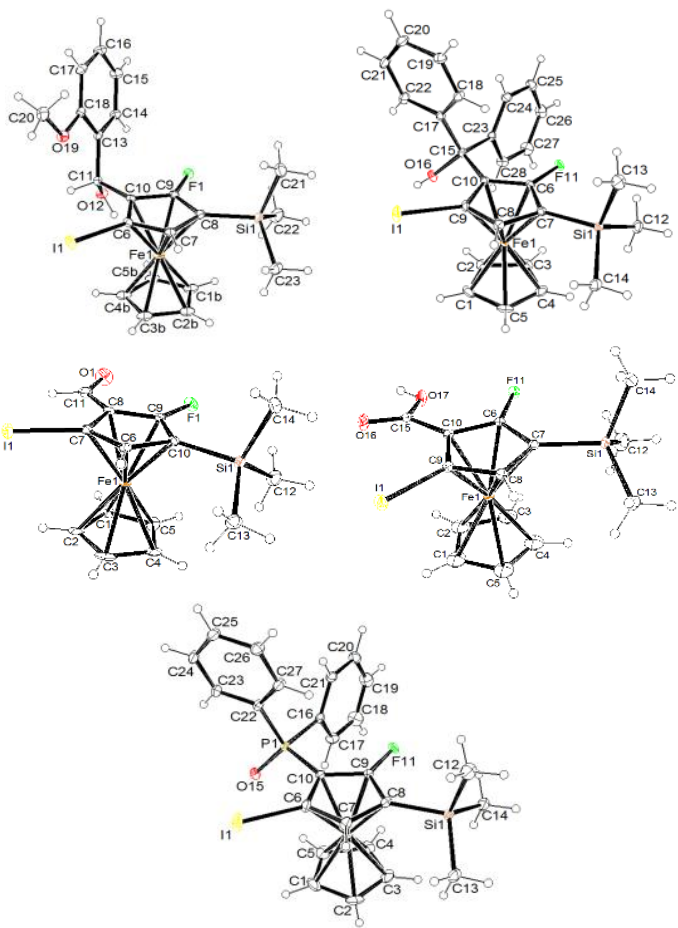

Fig. 7. ORTEP diagrams ( $30 \%$ probability) of compounds 5 s-I-2, 5 s-I-3, 5s-I-4, 5s-I5 and $5 s-1-7$

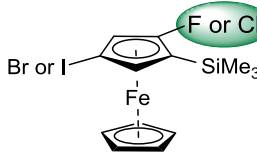

rac-4s-I (I, F)

rac-4s- $\mathrm{Br}(\mathrm{Br}, \mathrm{F})$

rac-4s'-I (I, Cl)

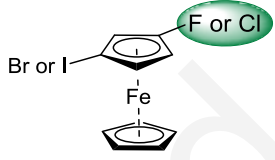

rac-6s-I: $91 \%$ yield $^{b}$ rac-6s-Br: $76 \%$ yield $^{b}$ rac-6s'-I: Quant. ${ }^{b}$
Scheme 4. Desilylation to afford 1,3-disubstituted ferrocenes 6. ${ }^{a}$ See ESI for more details. ${ }^{b}$ Yields are given after purification, as described in ESI.

With routes to 1,2 - and 1,3-disubstituted $(2,6), 1,2,3$ - and 1,2,4-trisubstituted (3, 4) and 1,2,3,4-tetrasubstituted (5) ferrocenes in hand, attention was next turned to complete the series with 1,2,3,4,5-pentasubstituted derivatives. Obtaining a fluoroferrocene with five different substituents on the same cyclopentanienyl ring is a substantial challenge. Indeed, apart $1,2,3,4,5$-pentafluoroferrocene, ${ }^{19 a}$ there was no $2,3,4,5$ tetrasubstituted fluoroferrocene reported until we started this study. ${ }^{23}$ To reach this goal, the silanes $5 \mathbf{s - 1}$ were considered unsuitable as starting materials because of the low propensity of the trimethylsilyl group to tolerate deprotolithiation at the neighboring position. ${ }^{28}$ Rather, the sulfide 3u-I (Scheme 5) was chosen as more suitable substrate. From $\mathbf{3 u - I}$ and chlorotrimethylsilane as the electrophile, the sequence of deprotonation-halogen dance-trapping reactions led to $1,3,4-$ trisubstituted 2-fluoroferrocene 5u-I (Fig. 8). Finally, pentasubstituted $\mathbf{7 u - I}$ was generated by deprotolithiation- trapping from $\mathbf{5 u}-\mathbf{I}$, this time by using dimethylformamide as electrophile, and isolated in $64 \%$ yield.

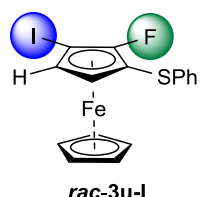

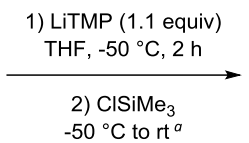

$-50{ }^{\circ} \mathrm{C}$ to rt $^{\circ}$

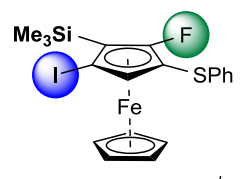

rac-5u-l: $45 \%$ yield $^{b}$

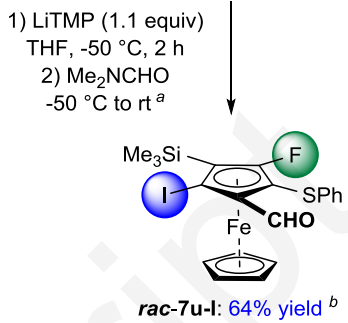

Scheme 5. Synthesis of a 2,3,4,5-tetrasubstituted fluoroferrocene 7. ${ }^{a}$ See ESI for more details. ${ }^{b}$ Yields are given after purification, as described in ESI.

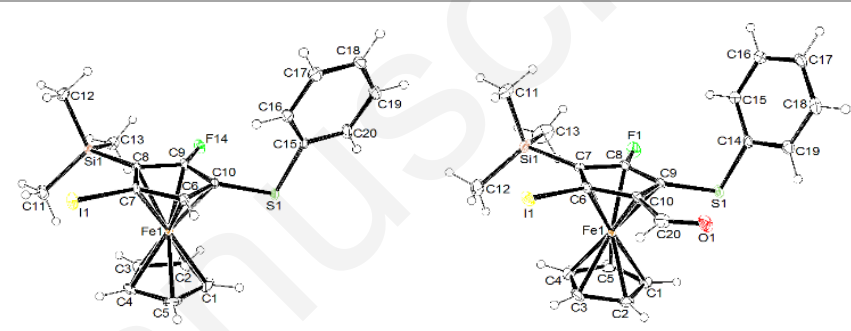

Fig. 8. ORTEP diagrams (30\% probability) of compounds $\mathbf{5 u - I}$ and $\mathbf{7 u - I .}$

\section{Conclusions}

Through the application of one or more fluorine-directed deprotolithiation steps in combination with the halogen 'dance' reaction, a large range of substituents could be easily introduced onto the fluoroferrocene core. These procedures allow the regioselective preparation of 1,2-di-, 1,3-di-, 1,2,3-tri, 1,2,4-tri-, 1,2,3,4-tetra- and 1,2,3,4,5-penta-substituted ferrocene derivatives in moderate to quantitative yields from the readily available fluoroferrocene (1), thereby considerably expanding the available chemical space. The ability to incorporate bromine, iodine or trialkyltin groups gives considerable scope for even further functionalization by crosscoupling or halogen/metal exchange reactions. Such secondgeneration manipulation of the substituent groups would serve to further increase the structural diversity of fluoroferrocene compounds. Therefore, the work described here provides both direct access to regioselectively functionalized fluoroferrocenes and entry points for further functionalization leading to fluoroferrocene-containing compounds which may in time find application in the preparation of compounds with materials science and biological applications.

\section{Conflicts of interest}

There are no conflicts to declare.

\section{Acknowledgements}


This work was supported by the Ministère de l'Enseignement supérieur, de la Recherche et de l'Innovation (grant to M.T.) and the Université de Rennes 1 . We also thank Rennes Métropole. We acknowledge the Fonds Européen de Développement Régional (FEDER; D8 VENTURE Bruker AXS diffractometer) and Thermofisher (generous gift of 2,2,6,6-tetramethylpiperidine). This research has been partly performed as part of the CNRS Laboratoire International Associé (LIA) project "Multipolar and Redox-active Organometallic Nanosized Assemblies for Molecular Photonics and Electronics".

\section{Notes and references}

1 (a) H. J. Son, W. Wang, T. Xu, Y. Liang, Y. Wu, G. Li and L. Yu, J. Am. Chem. Soc., 2011, 133, 1885; (b) A. C. Stuart, J. R. Tumbleston, H. Zhou, W. Li, S. Liu, H. Ade and W. You, J. Am. Chem. Soc., 2013, 135, 1806.

2 Y. Zhou, J. Wang, Z. Gu, S. Wang, W. Zhu, J. L. Aceña, V. A. Soloshonok, K. Izawa and H. Liu, Chem. Rev., 2016, 116, 422.

3 (a) N. A. Meanwell, J. Med. Chem., 2018, 61, 5822; (b) K. Müller, C. Faeh and F. Diederich, Science, 2007, 317, 1881; (c) B. G. de la Torre and F. Albericio, Molecules, 2019, 24, 809.

4 Z. Zong, W. Jing, J. Shi, S. a. Wen, T. Zhang, F. Huo, Y. Shang, Q. Liang, H. Huang and Y. Pang, Antimicrob. Agents Chemother., 2018, 62, e00165-18.

5 K. B. Dar, A. H. Bhat, S. Amin, R. Hamid, S. Anees, S. Anjum, B. A. Reshi, M. A. Zargar and S. A. Ganie, Curr. Top. Med. Chem., 2018, 18, 2702.

6 J.-L. Reymond, R. van Deursen, L. C. Blum and L. Ruddigkeit, MedChemComm, 2010, 1, 30.

7 (a) F. A. Larik, A. Saeed, T. A. Fattah, U. Muqadar and P. A. Channar, Appl. Organomet. Chem., 2017, 31, e3664; (b) D. Astruc, Eur. J. Inorg. Chem., 2017, 2017, 6

8 (a) T. J. Colacot, Chem. Rev., 2003, 103, 3101; (b) R. GómezArrayás, J. Adrio and J. C. Carretero, Angew. Chem. Int. Ed., 2006, 45, 7674; (c) V. C. Gibson, N. J. Long, P. J. Oxford, A. J. P. White and D. J. Williams, Organometallics, 2006, 25, 1932; (d) N. A. Butt, D. Liu and W. Zhang, Synlett, 2014, 25, 615.

9 F. W. Grevels, A. Kuran, S. Ozkar and M. Zora, J. Organomet. Chem., 1999, 587, 122.

10 A. Singh, I. Lumb, V. Mehra and V. Kumar, Dalton Trans., 2019, 48, 2840

11 M. Patra and G. Gasser, Nat. Rev. Chem., 2017, 1, 0066.

12 (a) Y. Wang, P. M. Dansette, P. Pigeon, S. Top, M. J. McGlinchey, D. Mansuy and G. Jaouen, Chem. Sci., 2018, 9, 70; (b) G. Jaouen, A. Vessières and S. Top, Chem. Soc. Rev., 2015, 44, 8802

13 (a) C. Biot, G. Glorian, L. A. Maciejewski, J. S. Brocard, O. Domarle, G. Blampain, P. Millet, A. J. Georges, H. Abessolo, D. Dive and J. Lebibi, J. Med. Chem., 1997, 40, 3715; (b) Y. C. Ong S. Roy, P. C. Andrews and G. Gasser, Chem. Rev., 2019, 119, 730.

14 A. Kondratskyi, K. Kondratska, F. Vanden Abeele, D. Gordienko, C. Dubois, C. Slomianny, P. Delcourt, E. Dewailly, R. Skryma, N. Prevarskaya, R.-A. Toillon, S. Lemière and C. Biot, Sci. Rep., 2017, 7, 15896.

15 F. L. Hedberg and H. Rosenberg, J. Organomet. Chem., 1971, 28, C14.

16 H. Butenschön, Synthesis, 2018, 50, 3787.
17 J. H. J. Peet and B. W. Rockett, J. Organomet. Chem., 1974, 82, C57.

18 K. Sünkel and S. Weigand, Inorg. Chim. Acta, 2011, 370, 224

19 (a) K. Sünkel, S. Weigand, A. Hoffmann, S. Blomeyer, C. G Reuter, Y. V. Vishnevskiy and N. W. Mitzel, J. Am. Chem. Soc., 2015, 137, 126; (b) D. Bulfield, M. Maschke, M. Lieb and N. Metzler-Nolte, J. Organomet. Chem., 2015, 797, 125; (c) M. S. Inkpen, S. Du, M. Hildebrand, A. J. P. White, N. M. Harrison, T. Albrecht and N. J. Long, Organometallics, 2015, 34, 5461. For a synthesis from bromoferrocene, see Ref. $19 b$.

20 H. Butenschön and G. Werner, Eur. J. Inorg. Chem., 2017, 2017, 378 .

21 Concerning deprotometalation-trapping in the ferrocene series, see: (a) C. J. Richards and A. J. Locke, Tetrahedron: Asymmetry, 1998, 9, 2377; (b) R. C. J. Atkinson, V. C. Gibson and N. J. Long, Chem. Soc. Rev., 2004, 33, 313; (c) B. Ferber and H. B. Kagan, Adv. Synth. Catal., 2007, 349, 493; (d) B. F. Bonini, M. Fochi and A. Ricci, Synlett, 2007, 360; (e) I. R. Butler, Eur. J. Inorg. Chem., 2012, 2012, 4387; (f) D. Schaarschmidt and H. Lang, Organometallics, 2013, 32, 5668.

22 (a) S. Gronowitz, Adv. Heterocycl. Chem., 1963, 14, 1; (b) G. Queguiner, F. Marsais, V. Snieckus and J. Epsztajn, Adv. Heterocycl. Chem., 1991, 52, 187; (c) J. Fröhlich, Prog. Heterocycl. Chem., 1994, 6, 1; (d) M. Schlosser, Eur. J. Org. Chem., 2001, 3975; (e) M. Schlosser, Angew. Chem. Int. Ed., 2005, 44, 376; ( $f$ ) X.-F. Duan and Z.-B. Zhang, Heterocycles, 2005, 65, 2005; $(g)$ M. Schlosser and F. Mongin, Chem. Soc. Rev., 2007, 36, 1161; (h) M. Schnürch, Top. Heterocycl. Chem., 2012, 27, 185; (i) W. Erb and F. Mongin, Tetrahedron, 2016, 72, 4973. Concerning studies on fluorine-free ferrocenes, see: (j) A. Zirakzadeh, A. Herlein, M. A. Gross, K. Mereiter, Y. Wang and W. Weissensteiner, Organometallics, 2015, 34, 3820; ( $k$ ) M. Tazi, W. Erb, Y. S. Halauko, O. A. Ivashkevich, V. E. Matulis, T. Roisnel, V. Dorcet and F. Mongin, Organometallics, 2017, 36, 4770; (I) G. Dayaker, A. Sreeshailam, F. Chevallier, T. Roisnel, P. Radha Krishna and F. Mongin, Chem. Commun., 2010, 46, 2862.

23 (a) M. Tazi, M. Hedidi, W. Erb, Y. S. Halauko, O. A. Ivashkevich, V. E. Matulis, T. Roisnel, V. Dorcet, G. Bentabed-Ababsa and F. Mongin, Organometallics, 2018, 37, 2207; (b) W. Erb and T. Roisnel, Chem. Commun., 2019, 55, 9132.

24 R. Sanders and U. T. Mueller-Westerhoff, J. Organomet. Chem., 1996, 512, 219.

25 C. F. Lavey, D. Hesk, S. Hendershot, D. Koharski, S. Saluja and P. McNamara, J. Labelled Compd. Radiopharm., 2007, 50, 264.

26 (a) D. Haas, J. M. Hammann, R. Greiner and P. Knochel, ACS Catal., 2016, 6, 1540; (b) E.-i. Negishi, Angew. Chem., Int. Ed., 2011, 50, 6738 .

27 N. Mokhtari Brikci-Nigassa, G. Bentabed-Ababsa, W. Erb and F. Mongin, Synthesis, 2018, 50, 3615.

28 F. Mongin, C. Curty, E. Marzi, F. R. Leroux and M. Schlosser, ARKIVOC, 2015, 48.

29 We also attempted to trap the lithio compound formed from 3r-I by dimethylformamide, but the expected carboxaldehyde decomposed in the course of the purification step. While it similarly proved impossible to isolate and characterize the ferrocene carboxaldehydes coming from $\mathbf{3 p - B r}$ and $\mathbf{3 p - I}$ due to their instability, the product formed from $3 p-C l(2,4-$ dichloro-3-fluoroferrocenecarboxaldehyde (5p-Cl); see $\mathrm{ESI}$ ) was fully characterized by NMR before its degradation.

30 B. Ferber, S. Top, R. Welter and G. Jaouen, Chem. Eur. J., 2006, 12, 2081. 